\title{
A Novel Comprehensive Procedure for Estimating Greenhouse Gas Emissions from Water Resource Recovery Facilities
}

\author{
R. Gori ${ }^{1(凶)}$, G. Bellandi ${ }^{1}$, C. Caretti $^{1}$, S. Dugheri ${ }^{2}$, A. Cosenza ${ }^{3}$, \\ V.A. Laudicina ${ }^{4}$, G. Esposito ${ }^{5}$, L. Pontoni ${ }^{5}$, D. Caniani ${ }^{6}$, \\ M. Caivano ${ }^{6,7}$, D. Rosso ${ }^{7,8}$, and G. Mannina ${ }^{3}$ \\ ${ }^{1}$ Department of Civil and Environmental Engineering (DICEA), \\ University of Florence, Via Santa Marta 3, 50139 Firenze, Italia \\ riccardo.gori@dicea.unifi.it \\ 2 Occupational Health Division, Careggi Hospital, \\ Largo P. Palagi 1, 50139 Firenze, Italia \\ 3 Department of Civil, Environmental, Aerospace, Materials Engineering, \\ University of Palermo, Viale delle Scienze, 90128 Palermo, Italy \\ ${ }^{4}$ Department of Agricultural and Forest Sciences, University of Palermo, \\ Viale Delle Scienze Edificio 4, 90128 Palermo, Italy \\ 5 Department of Civil and Mechanical Engineering, \\ University of Cassino and Southern Lazio, \\ Via Di Biasio 43, 03043 Cassino (FR), Italy \\ ${ }^{6}$ School of Engineering, University of Basilicata, \\ Viale Dell'Ateneo Lucano 10, 85100 Potenza, Italy \\ 7 Department of Civil and Environmental Engineering, \\ University of California, Irvine, CA 92697-2175, USA \\ ${ }^{8}$ Water-Energy Nexus Center, University of California, \\ Irvine, CA 92697-2175, USA
}

\begin{abstract}
The emissions of the major greenhouse gases (GHGs), i.e. carbon dioxide $\left(\mathrm{CO}_{2}\right)$, methane $\left(\mathrm{CH}_{4}\right)$, and nitrous oxide $\left(\mathrm{N}_{2} \mathrm{O}\right)$ from water resource recovery facilities (WRRFs) are of increasing concern in the water industry. In order to produce useful and comparable information for monitoring, assessing, and reporting GHG emissions from WRRFs, there is a need for a generally accepted methodology for their quantification. This paper aims at proposing the first protocol for monitoring and accounting for GHG emissions from WRRFs, taking into account both direct and indirect internal emissions and focusing the attention on plant sections known to be primarily responsible for GHG emissions (i.e. oxidation tanks and sludge digestors). The main novelties of the proposed protocol are: (i) measurement of direct internal emissions ascribed to aeration devices; (ii) estimation of indirect internal emissions derived from field measurement; (iii) GHG emission offset due to biogas energy recovery quantified by monitoring biogas composition in case of anaerobic digestion. Finally, the proposed methodology enables and allows the gathering of useful information on plants (e.g. energetic efficiency of the aeration device system and composition of biogas produced in anaerobic digestion) to address potential strategies for improving the plants' performance.
\end{abstract}


Keywords: Carbon footprint · Methane ' Nitrous oxide • Off-gas · Wastewater · Energy

\section{Introduction}

The emissions of the major greenhouse gases (GHGs), i.e. carbon dioxide $\left(\mathrm{CO}_{2}\right)$, methane $\left(\mathrm{CH}_{4}\right)$, and nitrous oxide $\left(\mathrm{N}_{2} \mathrm{O}\right)$ from water resource recovery facilities (WRRFs) are of increasing concern in the water industry (Caivano et al. 2016; Caniani et al. 2016; Kampschreur et al. 2008). In order to produce useful and comparable information for monitoring, assessing, and reporting GHG emissions from WRRFs, there is a need for a generally accepted methodology for their quantification.

$\mathrm{CO}_{2}$ is directly produced in aerobic biological processes by the oxidation of organic compounds accompanied by cell growth. $\mathrm{CO}_{2}$ derived from wastewater treatment is assumed to originate from short-lived biogenic material (IPCC 2006), however, fossil organic carbon was found in the incoming wastewater of WRRFs and related to direct fossil $\mathrm{CO}_{2}$ emissions from oxidation by activated sludge (AS), depending in the extent, on wastewater composition and treatment configuration (Law et al. 2013). $\mathrm{N}_{2} \mathrm{O}$ is currently the single most important ozone-depleting gas (Ravishankara 2009). $\mathrm{N}_{2} \mathrm{O}$ emissions occurring in aerated zones are lined to nitrogen load, volumetric stripping, and the role of ammonia-oxidizing bacteria (Daelman et al. 2015; Guo et al. 2013). Stenström et al. (2014) have found that $\mathrm{N}_{2} \mathrm{O}$ formed in liquid phase during denitrification accumulates mainly in the water volume until aeration starts and thereafter it is quickly stripped off to the atmosphere. Similarly, this can happen for $\mathrm{CH}_{4}$. Although methanogenic activity in AS tanks is deemed to be insignificant (Gray et al. 2002), dissolved $\mathrm{CH}_{4}$ can enter aerobic AS reactors, where is stripped or biologically oxidized (Daelman et al. 2012), from sewers (Guisasola et al. 2008) or sections of the WWTPs where anaerobic conditions occur, e.g. in anaerobic selectors (Techobanoglous et al. 2014; Wentzel et al. 2008). Therefore, beside the actual GHG production occurring in aeration tanks, stripping induced by aeration is one of the main causes making this compartment one of the major contributors to WRRF direct emissions.

This paper aims at proposing the first protocol for monitoring and accounting for GHG emissions from WRRFs, taking into account both direct and indirect internal emissions and focusing the attention on plant sections known to be primarily responsible for GHG emissions (i.e. oxidation tanks and sludge digestors). The main novelties of the proposed protocol are: (i) measurement of direct internal emissions ascribed to aeration devices; (ii) estimation of indirect internal emissions derived from field measurement; (iii) GHG emission offset due to biogas energy recovery quantified by monitoring biogas composition in case of anaerobic digestion.

Finally, the proposed methodology enables and allows the gathering of useful information on plants (e.g. energetic efficiency of the aeration device system and composition of biogas produced in anaerobic digestion) to address potential strategies for improving the plants' performance. 


\section{Estimation of Indirect Emission from Aerated Tanks}

The off-gas technique (Redmon et al. 1983) is proposed as a method for estimating indirect GHG emissions from aerated tanks (oxidation tanks and aerobic stabilization tanks) from plants using diffused air aeration systems. The layout of the proposed device is represented in Fig. 1.

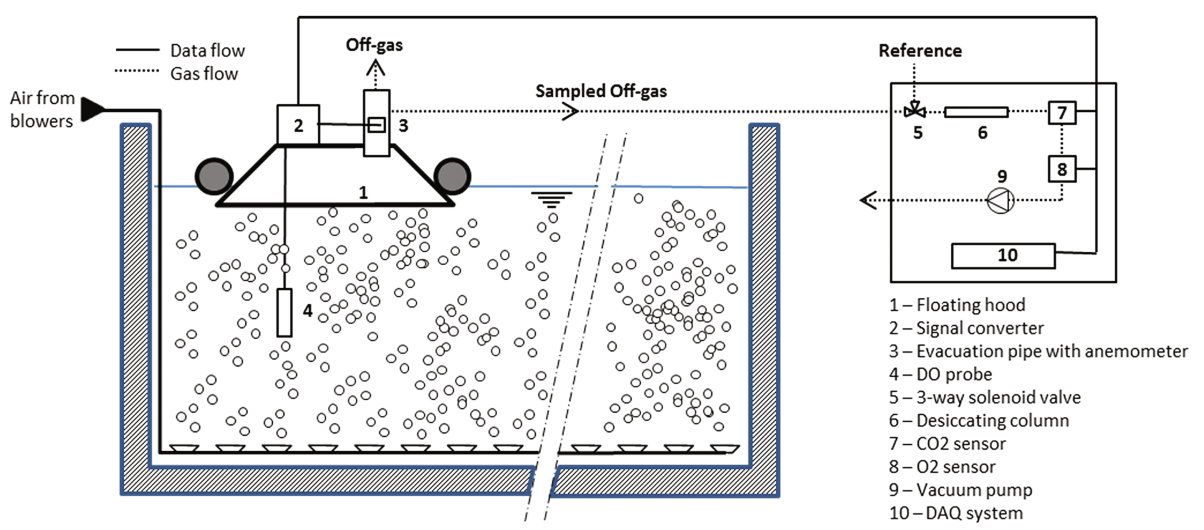

Fig. 1. Schematic layout of the off-gas analyzer for measuring OTE in aerated tanks

The methodology also has the potential for:

- monitoring the trend of fouling and scaling of diffusers which can affect their operation and efficiency and, therefore, energy consumption and indirect GHG emissions;

- investigating the relationship between air flow-rate and OTE.

A floating hood captures the off-gas leaving the tank surface and the flow rate is measured by a hot wire anemometer. The system is also equipped with a probe for measuring DO in the liquid phase, required for correcting the OTE to standard conditions (i.e. $\alpha$ SOTE). The captured stream is sent to an off-gas analyzer for analysis of $\mathrm{O}_{2}$ and $\mathrm{CO}_{2}$.

In cases of aeration systems that use blowers, it is possible to derive the actual power $\left(\mathrm{P}_{\mathrm{w}}\right)$ used by blowers with the adiabatic compression formula (Eq. 1).

$$
P_{w}(k W)=\frac{Q_{t o t} \cdot P_{1}}{17.4 \cdot e_{M} \cdot e_{B}} \cdot\left[\left(\frac{P_{2}}{P_{1}}\right)^{0.283}-1\right]
$$

$\mathrm{Q}_{\text {tot }}$ is the total air flow rate $\left(\mathrm{m}^{3} / \mathrm{min}\right), \mathrm{e}_{\mathrm{M}}$ is the motor efficiency (dimensionless), $\mathrm{e}_{\mathrm{B}}$ is the blower efficiency (dimensionless), $\mathrm{P}_{1}$ and $\mathrm{P}_{2}$ are the inlet and outlet absolute pressure $(\mathrm{kPa})$, respectively. Specifications of the blower $\mathrm{P}_{2}$ can be derived from the relative characteristic curve $\left(\mathrm{P}_{1}\right.$ is always $\sim 0.95$ of the atmospheric pressure due to the inlet suction). Energy consumption is calculated by integrating $\mathrm{P}_{\mathrm{w}}$ over time (Eq. 2), 
and can thus be used to calculate and account for the blowers contribution to indirect internal emissions:

$$
\text { Internal indirect GHG emission (IIE) }\left[\frac{k g C O_{2, e q}}{d}\right]=\int k \cdot P_{w} d t
$$

In the case of static power generation portfolios, or due to unavailability of data, the carbon emission intensity for power generation $(\mathrm{k}, \mathrm{kgCO} 2$, eq/ $\mathrm{kWh})$ can be taken out of the integral and which converts to the cumulative energy consumption. The measured air flow can be normalized for the area covered by the hood and extended in the proximity of each measurement point so that the whole tank surface is virtually covered.

\section{Estimation of Direct Emission from Aerated Tanks}

The estimation of direct emission from aerated tanks (i.e. AS and aerobic digesters) requires the monitoring of both off-gas flow rate and GHG concentration in the off-gas of aerated tanks. Because operating conditions (e.g. DO, COD/N ratio, ammonium concentration) are variable both in time and space, direct emission of GHGs are expected to be variable as well. For this reason, unless aerated tanks are covered, the procedure suggests a simultaneous multi-point monitoring of aerated tanks using floating hoods. The procedure proposed here suggests to carry out from 2 to 4 campaigns per year in order to cover the entire possible temperature range and appreciate seasonal variations of phenomena affecting the GHG emissions. In order to appreciate the diurnal variations within a single campaign, online and high-frequency devices should be adopted. Measurements should be done every 10-20 min by monitoring GHG concentration in the off-gas for a minimum of $24 \mathrm{~h}$ up to one week. In the case of multiple day monitoring, it is preferable to also include weekend samples, which significantly contribute to increase the GHG emissions estimation accuracy (Daelman et al. 2015).

The procedure suggests the use of the IR analyzer due to its measurement accuracy and the ease of operation. The instrument should compensate for temperature fluctuations and water vapor interference, and other gases known to potentially bias the measurements. An alternative to IR for online monitoring of $\mathrm{CO}_{2}, \mathrm{~N}_{2} \mathrm{O}$, and $\mathrm{CH}_{4}$ is the micro-Gas Chromatograph (GC) equipped with two columns, divided in two parallel channels, using $\mathrm{He}$ as carrier gas. Channel 1, equipped with a PoraPlotQ (PPQ) and Channel 2, with a divinylbenzene-ethyleneglycol-dimethacrylate polymer column. The analytical performance is ensured by the chromatographic technology allowing for components' separation and, therefore, for very accurate measurements. Although it is not yet as popular as IR based tools, this instrument is characterized by a compact design that makes it as portable as other online monitoring equipment. 


\section{Estimation of GHG's Direct Emission from Biogas Combustion}

One of the main concerns in anaerobic digestion (AD) is acidification of the medium which can also lead to, amongst other problems, an increase in $\mathrm{H}_{2}$ production in the biogas due the inhibition of the hydrogenotrophic methanogenesis. With regards to GHG emissions, the presence of $\mathrm{H}_{2}$ in the biogas is known to be responsible for a higher NOx production in the exhaust fumes from the process of biogas conversion to energy. It is strongly suggested to monitor $\mathrm{H}_{2}$ levels in the biogas, not only to control the state of the anaerobic reactors, but also to prevent potential GHG emissions.

In order to estimate direct GHG emissions due to biogas combustion, the procedure suggests to measure:

- BMP of the sludge;

- percent composition of the biogas to optimize the power production with particular reference to the $\mathrm{CH}_{4} / \mathrm{CO}_{2}$ ratio;

- percentage of $\mathrm{H}_{2}$ in the biogas.

Table 1. Summary of existing protocols for GHG emissions from WRRFs derived from literature

\begin{tabular}{l|l|l|l|l|l}
\hline Reference & $\begin{array}{l}\text { Type } \\
\text { of } \\
\text { sample }\end{array}$ & $\begin{array}{l}\text { Gas flux } \\
\text { measurement }\end{array}$ & $\begin{array}{l}\text { Use } \\
\text { Emission } \\
\text { Factor }\end{array}$ & $\begin{array}{l}\text { Quantified } \\
\mathrm{GHG}\end{array}$ & Remarks \\
\hline $\begin{array}{l}\text { Monteith } \\
\text { et al. 2005 }\end{array}$ & - & No & No & $\mathrm{CO}_{2}, \mathrm{CH}_{4}$ & $\begin{array}{l}\text { Carbon mass balance } \\
\text { and energy balance } \\
\text { of sections for liquid } \\
\text { and solids treatment. }\end{array}$ \\
\hline $\begin{array}{l}\text { IPCC } \\
2006\end{array}$ & - & No & Yes & $\mathrm{N}_{2} \mathrm{O}, \mathrm{CH}_{4}$ & $\begin{array}{l}\text { GHG emissions } \\
\text { estimate based on } \\
\text { EFs associated with } \\
\text { specific populations } \\
\text { and type of WRRFs. }\end{array}$ \\
\hline $\begin{array}{l}\text { USEPA } \\
2007\end{array}$ & - & No & Yes & $\mathrm{N}_{2} \mathrm{O}, \mathrm{CH}_{4}$ & $\begin{array}{l}\text { Based on the } \\
\text { procedure proposed } \\
\text { by IPCC (2006). }\end{array}$ \\
\hline CEC 2006 & - & No & Yes & $\mathrm{N}_{2} \mathrm{O}, \mathrm{CH}_{4}$ & $\begin{array}{l}\text { Simplified version of } \\
\text { the IPCC protocol } \\
\text { (IPCC 2006). }\end{array}$ \\
\hline $\begin{array}{l}\text { GWRC } \\
2011\end{array}$ & $\begin{array}{l}\text { Gas } \\
\text { and } \\
\text { liquid }\end{array}$ & Yes & No & $\mathrm{N}_{2} \mathrm{O}, \mathrm{CH}_{4}$ & $\begin{array}{l}\text { Based on full-scale } \\
\text { data to establish new } \\
\text { emission factors than } \\
\text { the IPCC ones. }\end{array}$ \\
\hline $\begin{array}{l}\text { Chandran } \\
2011\end{array}$ & $\begin{array}{l}\text { Gas } \\
\text { and } \\
\text { liquid }\end{array}$ & Yes & No & $\begin{array}{l}\text { Combines real-time } \\
\text { measurement of gas } \\
\text { with discrete } \\
\text { measurements of } \\
\text { liquid. }\end{array}$ \\
\hline
\end{tabular}


Monitoring of the biogas composition also allows the calculation of a reliable $\mathrm{CO}_{2}$, eq offset due to energy recovery from biogas which is proportional to the biogas produced and biogas composition. The combustion gas can be analyzed in order to assess the real $\mathrm{CH} 4$ oxidation efficiency during combustion Table 1.

\section{Total GHG Emission and CFP}

To determine the total CFP, all sources must be converted to $\mathrm{CO}_{2}$,eq multiplying emission of $\mathrm{N}_{2} \mathrm{O}$ and $\mathrm{CH}_{4}$ times their respective GWP (i.e. 298 end 25 respectively, IPCC 2006). For space reason, details will be provided in the full paper.

\section{Conclusions}

The protocol presented in this paper contains a selection of available measurements methods for GHG detection and CFP assessment for different applications. This selection was based on field measurements and laboratory tests to validate the capabilities of each analytical and theoretical technique. The main novelties of the proposed protocol are: (i) measurement of direct internal emissions ascribed to aeration devices, generally reported as the most important contributors to WRRF CFP; (ii) estimation of indirect internal emissions derived from field measurement, which are not always easy to assess as it depends on the grade at which the plant is monitored and online data are logged; (iii) monitoring the biogas composition for considering a GHG emission offset due to energy recovery in case of the presence of an anaerobic digester, as an alternative method for a double purpose (i.e. biogas quality monitoring and GHG emission limitation).

GHG emissions from aerated AS tanks are the major contributors to direct emissions of a WRRF. Literature studies highlight the potential of this compartment in emitting GHG generated already in the sewer or in other plant compartments (e.g. primary settlers, pre-denitrification tanks). In this view, this paper focuses on direct GHG emissions at the aeration tank considering a valuable assumption for regular plant design. In those cases where the wastewater flow would be extensively agitated before entering the aeration tank a dedicated assessment of this particular section should be considered.

Existing measurement techniques and conversion methods were selected in order to define the best combination of solutions in the framework of quantifying the overall CFP of WRRFs.

\section{References}

Caivano M, Bellandi G, Mancini IM, Masi S, Brienza R, Panariello S, Gori R, Caniani D (2016) Monitoring the aeration efficiency and carbon footprint of a medium-sized WWTP: experimental results on oxidation tank and aerobic digester. Environ Technol, 1-10 
Caniani D, Esposito G, Gori R, Caivano M, Masi S, Cosenza A, Abuissa A, Mannina G (2016) Towards a reduction of Greenhouse Gas emission from wastewater treatment plants: a new plant wide experimental and modelling approach. In: SIDISA 2016, X International Symposium on Sanitary and Environmental Engineering, Rome, 19-23 June 2016

CEC (2006) Inventory of California Greenhouse Gas Emissions and Sinks: 1990 to 2004. Sacramento, CA

Chandran K (2011) Protocol for the Measurement of Nitrous Oxide Fluxes from Biological Wastewater Treatment Plants. In: Methods in Enzymology. Elsevier Inc., pp. 369-385

Daelman MRJ, van Voorthuizen EM, van Dongen UGJM, Volcke EIP, van Loosdrecht MCM (2012) Methane emission during municipal wastewater treatment. Water Res 46:57-70

Daelman MRJ, van Voorthuizen EM, van Dongen UGJM, Volcke EIP, van Loosdrecht MCM (2015) Seasonal and diurnal variability of N2O emissions from a full-scale municipal wastewater treatment plant. Sci Total Environ 536:1-11

Gray ND, Miskin IP, Korniova O, Curtis TP, Head IM (2002) Occurrence and activity of Archaea in aerated activated sludge wastewater treatment plants. Environ Microbiol 4:158-168

Guisasola A, de Haas D, Keller J, Yuan Z (2008) Methane formation in sewer systems. Water Res 42:21-30

Guo L.S, Lamaire-chad C, Bellandi G, Daelman MRJ, Maere T, Nous J, Flameling T, Weijers S, Mark CM, Loosdrecht V, Volcke EIP, Nopens I, Vanrolleghem PA (2013) High frequency field measurements of Nitrous oxyde (N2O) Gas Emissions and Influencing Factors at WWTPs under Dry and Wet Weather Conditions. In: WEF/IWA Nutrient Removal and Recovery 2013

GWRC, 2011. N2O and $\mathrm{CH} 4$ emission from wastewater collection and treatment systems, London

IPCC (2006) Guidelines for National Greenhouse Gas Inventories. Prepared by the National Greenhouse Gas Inventories Programme, Kanagawa

Kampschreur MJ, van der Star WRL, Wielders HA, Mulder JW, Jetten MSM, van Loosdrecht MCM (2008) Dynamics of nitric oxide and nitrous oxide emission during full-scale reject water treatment. Water Res 42:812-826

Law Y, Jacobsen GE, Smith AM, Yuan Z, Lant P (2013) Fossil organic carbon in wastewater and its fate in treatment plants. Water Res 47:5270-5281

Monteith HD, Sahely HR, MacLean HL, Bagley DM (2005) A rational procedure for estimation of greenhouse-gas emissions from municipal wastewater treatment plants. Water Environ Res 77:390-403

Ravishankara AR (2009) Nitrous Oxyde (N2O): The Dominant Ozone-Depleting Substance Emitted in the 21st Century. Science 326(80):123-125

Redmon DT, Boyle WC, Ewing L (1983) Oxygen transfer efficiency measurements in mixed liquor using off-gas techniques. Water Pollut Control Fed 55:1338-1347

Stenström F, Tjus K, La Cour Jansen J (2014) Oxygen-induced dynamics of nitrous oxide in water and off-gas during the treatment of digester supernatant. Water Sci Technol 69:84-91

Techobanoglous G, Burton FL, Stensel HD (2014) Wastewater Engineering: Treatment and Reuse, 5th edn. Metcalf and Eddy, McGraw-Hill series in civil and environmental engineering. McGraw-Hill, New York

USEPA (2007) Inventory of U.S. Greenhouse Gas Emissions and Sinks: 1990-2005. US Environmental Protection Agency, Washington DC

Wentzel MC, Comeau Y, Ekama GA, van Loosdrecht MCM, Brdjanovic D (2008) Enhanced biological phosphorus removal, Biological waste water treatment. Principles, Model Des, 155-170. IWA Publ. 